\title{
4H-SiC Epitaxial Layers Grown on on-axis Si-face Substrate
}

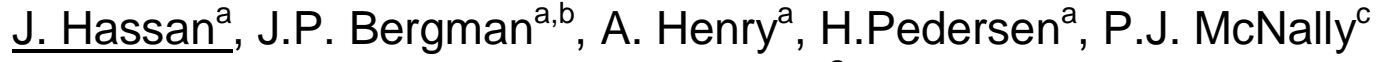 \\ and E. Janzén ${ }^{\mathrm{a}}$ \\ ${ }^{a}$ Department of Physics, Chemistry and Biology, IFM \\ Linköping University, S-58183 Linköping, Sweden

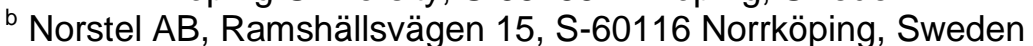 \\ 'Nanomaterials Processing Laboratory, Research Institute for Networks \& Communications \\ Engineering (RINCE), School of Electronic Engineering, \\ Dublin City University, Dublin 9, Ireland \\ Tel: +46 132823 80, Fax: +46 131423 37, Email: jawul@ifm.liu.se
}

Keywords: Chemical vapor deposition, On-axis, X-ray topography, AFM, 4H-SiC, SWBXT

\begin{abstract}
We report on the growth of $4 \mathrm{H}-\mathrm{SiC}$ epitaxial layer on 2" full wafer Si-face polished nominally onaxis substrates, using Hot-Wall epitaxy. The polytype stability has been maintained over the larger part of the wafer, but 3C inclusions have not been possible to avoid. Special attention has given to the mechanism of generation and propagation of 3C polytype in $4 \mathrm{H}-\mathrm{SiC}$ epilayer. Different optical and structural techniques were used to characterize the material and to understand the growth mechanisms. It was found that all $3 \mathrm{C}$ inclusions were generated at the interface between the substrate and the epitaxial layer, and no $3 \mathrm{C}$ inclusions were initiated at later stages of the growth.
\end{abstract}

\section{Introduction}

In high power electronic applications $4 \mathrm{H}-\mathrm{SiC}$, due to its wider band gap, high breakdown electric field and high thermal conductivity, has proven to be a superior semiconductor material as compared to conventional semiconductor materials like $\mathrm{Si}$ and GaAs [1]. The availability of increasing diameter of single crystal $4 \mathrm{H}-\mathrm{SiC}$ wafer has opened up the possibilities for many power applications in recent years. The (00.1) Si-face polished, off-cut $\left(4^{\circ}\right.$ or $\left.8^{\circ}\right)$ substrates are normally used to grow active layer for $\mathrm{SiC}$ electronic devices. With the increasing wafer diameter this offangle results in material losses when wafers are sliced from a boule [2]. Epitaxial layer grown on off-cut wafer on one hand easily replicates the polytype of the substrate, but on other hand makes it possible for basal plane dislocations to penetrate into the epilayer from off-cut substrate. It has reported before that after long operation of bipolar electronic devices under heavy load basal plane dislocations in the epilayer dissociate into two partials, one stationary and one moving thus result in the formation of stacking faults which ultimately degrade forward voltage [3]. The replication of basal plan dislocations into epilayer can be avoided through growth on on-axis substrate. One of the major issue with on-axis growth on (00.1) Si-face is the nucleation of 3C-SiC inclusions which reduces the effective useable area on full wafer for device purpose [4]. Therefore, it is crucial to investigate the origin and propagation of $3 \mathrm{C}-\mathrm{SiC}$ on $4 \mathrm{H}-\mathrm{SiC}$ on-axis substrate.

\section{Experimental}

A horizontal hot-wall CVD reactor [5] was used for the growth of n-type low doped, thick epilayers on Si-face on-axis substrate. The growth temperature and pressure were $1560{ }^{\circ} \mathrm{C}$ and $200 \mathrm{mbar}$, respectively. Hydrogen purified through heated palladium membrane was used as carrier gas while silane and propane were used as the sources for $\mathrm{Si}$ and $\mathrm{C}$, while $\mathrm{C} / \mathrm{Si}=1$. Nitrogen was used as ntype dopent. In situ high temperature treatment was performed on all samples for 10 minutes in a mixture of hydrogen and propane before growth. In order to reveal 3C parts in the epilayer different methods like molten $\mathrm{KOH}$ etching, high resolution X-ray diffraction (HRXRD) and illumination of epilayer under UV laser light at $77 \mathrm{~K}$ was performed. Surface morphology was observed under optical microscope with Nomarski interface contrast while the surface roughness was measured with tapping mode atomic force microscopy (AFM). Minority carrier lifetime mapping was 


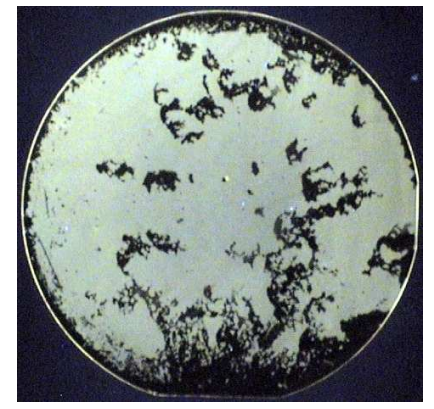

(a)

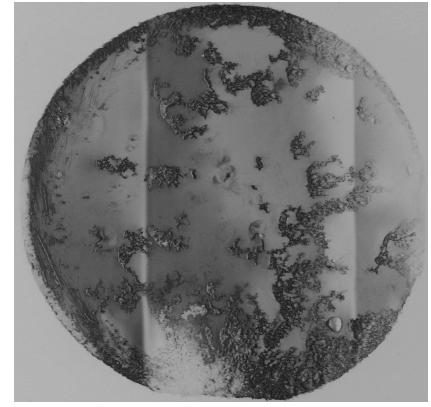

(b)

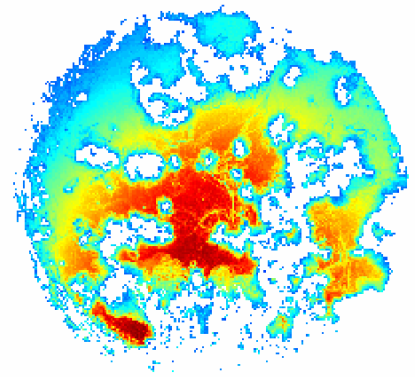

(c)

Fig. 1 Full wafer images of thick $4 \mathrm{H}$ on-axis grown epitaxial layer. a) Image taken with UV light illumination at $77 \mathrm{~K}$. The black areas correspond to $3 \mathrm{C}-\mathrm{SiC}$ while the rest is $4 \mathrm{H}-\mathrm{SiC}$. b) $\mathrm{X}$ ray topographic map of full wafer taken with in-house facility. The black areas are $3 \mathrm{C}$ while gray areas are $4 \mathrm{H}-\mathrm{SiC} . \mathrm{C}$ ) Carrier life time map at room temperature. White spots are $3 \mathrm{C}$ while the rest is $4 \mathrm{H}-\mathrm{SiC}$.

performed on full wafer at room temperature. Synchrotron white beam X-ray topography (SWBXT) was performed with the synchrotron radiation from the bending magnet source of the DORIS III storage ring at HASYLAB-DESY, in Hamburg. SWBXT was made in back reflection mode on some selected areas of the sample while full wafer maps were recorded using a Bede Lang X-ray topograph. In order to observe the lateral expansion of 3C nuclei, wafer was cut around 3C inclusion and polished from both sides to reach the area on substrate where $3 \mathrm{C}$ nucleation had started at substrate/epi interface. Also a part of wafer with $3 \mathrm{C}$ inclusions in it was then polished from epilayer side in steps of $20 \mu \mathrm{m}$ and images were recorded with optical microscope after each step.

\section{Results and Discussion}

A typical result from an epitaxial growth on on-axis substrate is shown in Fig. 1. The figure shows a full wafer mapping using different experimental techniques. Image taken with UV illumination at $77 \mathrm{~K}$ is shown in Fig.1a where black areas are related to $3 \mathrm{C}$ inclusions while the remaining part is 4H-SiC. Fig. 1b shows a X-ray topographic image of full wafer where black area corresponds to 3C parts while gray area is $4 \mathrm{H}-\mathrm{SiC}$. Figure 1c, shows a mapping of the photoluminescence decay time at room temperature. The white areas correspond to the $3 \mathrm{C}$ inclusions where no optical signal at the $4 \mathrm{H}$ band gap is present. The presence of $3 \mathrm{C}$ polytype inclusions in $4 \mathrm{H}$ were further confirmed with HRXRD. 3C inclusions spread randomly on the wafer with typically higher density at the edges of the wafer which could be due to bad crystal quality of the wafer at edges and rougher surface because of polishing scratches. The surface morphology of epilayer observed under optical microscope shows that $4 \mathrm{H}$ parts grew in columns while $3 \mathrm{C}$ parts are more flat as shown in Fig. 2. Screw dislocations are the main nucleation center where growth occurs through the spiral growth mechanism. The spiral wounds and forms a pyramid structure around dislocation. This columnar growth of $4 \mathrm{H}$ parts could be due to low ad-atom mobility which results in slow lateral growth and hence macro step bunching. 3C inclusion formation on $4 \mathrm{H}$ substrate strongly depends on the face polarity with high density of $3 \mathrm{C}$ on Si face and almost no $3 \mathrm{C}$ on $\mathrm{C}$

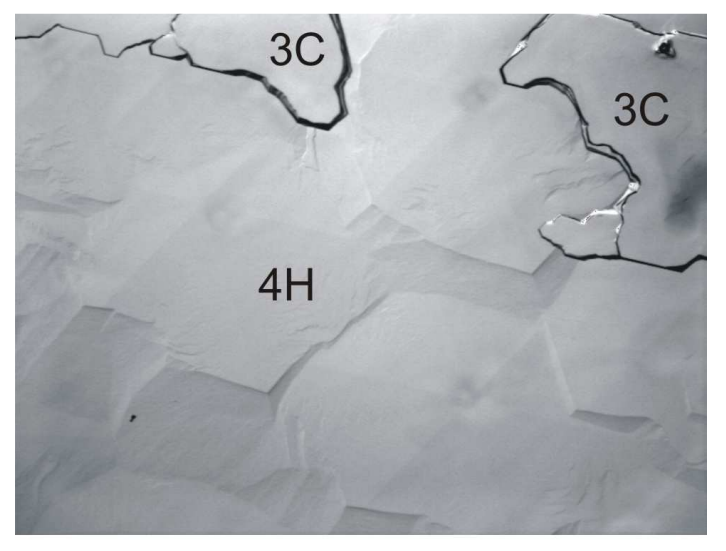

Fig. 2 Optical image taken from as grown epilayer showing 3C inclusions in $4 \mathrm{H}-\mathrm{SiC}$. $3 \mathrm{C}$ parts are more flat as compared to $4 \mathrm{H}$ parts. 


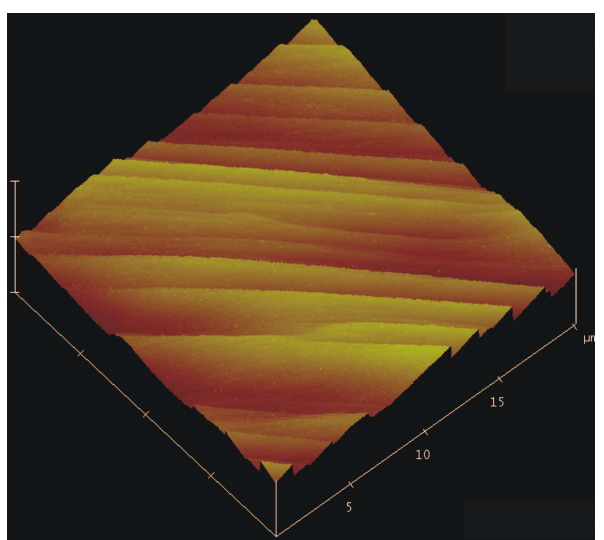

(a)

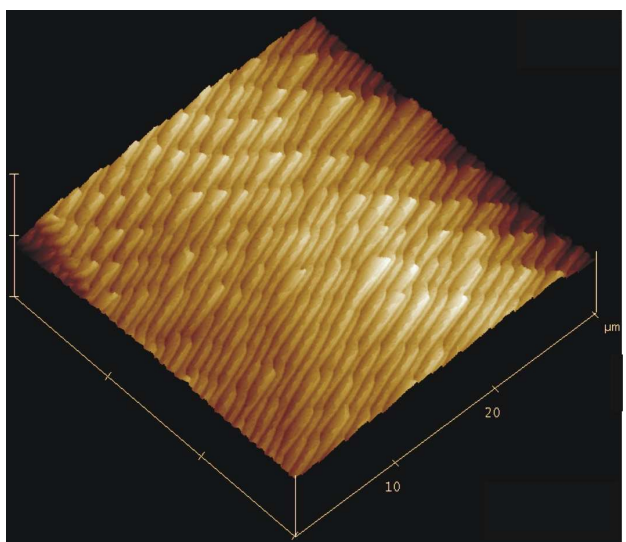

(b)

Fig. 3 a) 20x20 $\mu \mathrm{m}$ AFM image taken from 3C part. Step height ranging from one bilayer to a few bilayers while RMS is $2 \mathrm{~nm}$ b) $20 \times 20 \mu \mathrm{m}$ AFM image taken from $4 \mathrm{H}$ part. Step height is unit c while RMS is $0.8 \mathrm{~nm}$

face which could be due to different surface free energy with high surface free energy on Si face. In order to reduce surface free energy step bunching (hills and valleys) occurs which results in rougher surface. Local growth front destabilization due to local suppression of step-flow mode on substrate imperfections also causes step bunching and results in small (0001) facets. On such facets 3D nucleation of $3 \mathrm{C}$ is radically favored. In many cases flat terraces with dimensions of several hundred $\mu \mathrm{m}$ (which is much larger than the diffusion length of ad-atoms) due to step bunching have seen without any $3 \mathrm{C}$ nucleation on it. This clearly shows that the growth conditions used are not favorable to start 3D nucleation of $3 \mathrm{C}$ on flat terraces. Same could be true at the beginning of the growth and 3C nucleated not through 3D nucleation but due to bad preparation of the surface.

The surface morphology of $4 \mathrm{H}$ and 3C-SiC parts was studied by AFM in tapping mode. Fig. 3a shows the AFM image taken on $3 \mathrm{C}$ part. The surface roughness over $20 \times 20 \mu \mathrm{m}$ area is $2 \mathrm{~nm}$ and step height is not uniform ranging from one bilayer to a few of bilayers. Fig. 3b presents $20 \times 20 \mu \mathrm{m}$ scan over $4 \mathrm{H}$ parts where the surface roughness is $0.8 \mathrm{~nm}$ and the step height is unit cell height $\mathrm{c}$. The step height is more uniform close to the center of the spiral while it gets worst away from the center of spiral because of step bunching.

Growth has been made on both as polished and on $\mathrm{KOH}$ etched wafer, without any significant difference. The $\mathrm{KOH}$ etched wafers also revealed the presence of dislocations, and it was found that there was less probability for $3 \mathrm{C}$ nucleation in the areas with high dislocation density (excluding grain boundaries), probably due to the reason that more steps and kinks are available in that area and the distance between two growth centers is less than the ad-atom diffusion length. In order to observe the lateral expansion of $3 \mathrm{C}$ nuclei, the wafer was cleaved and polished from both sides to reach the area on the substrate where $3 \mathrm{C}$ nucleation had started, as shown in Fig. 4. Optical images taken from the part of wafer polished from epilayer side in steps of $20 \mu \mathrm{m}$ showed that $3 \mathrm{C}$ inclusions started at the epilayer-substrate interface at the beginning of the growth run and expanded laterally. It also uncovered some $4 \mathrm{H}$ parts in $3 \mathrm{C}$ patches which were over grown by $3 \mathrm{C}$ during growth. No $3 \mathrm{C}$ inclusions were found that started at later stages during the growth. A particular attention has focused to the areas in the epilayer where two spirals meet. No $3 \mathrm{C}$ is seen to be nucleated in those areas. The $3 \mathrm{C}$ parts, nucleated at the substrate surface seem to propagate laterally between these spirals. Also no $3 \mathrm{C}$ parts were seen to originate from micropipes and no disturbance of the surface morphology or other epilayer defects related to micropipes, like half moon and wavy pits, were observed in the vicinity of micropipe as seen in the case of off-axis substrate. This could be due to different growth mechanism in case of on-axis substrate as compared to off-axis substrate. 


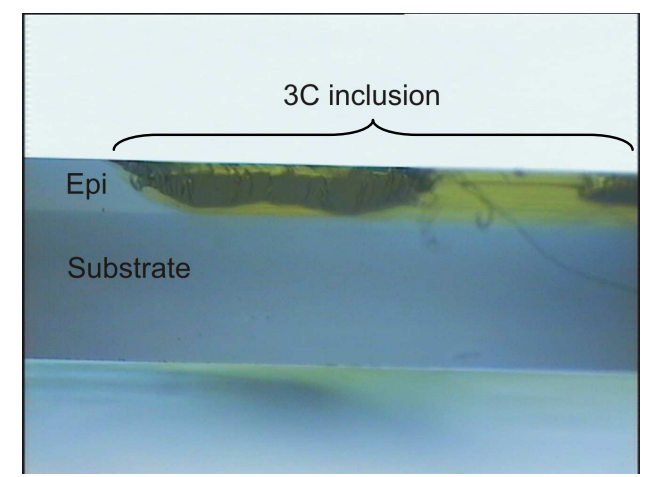

Fig. 4 Optical image of the cross-section of wafer showing $3 \mathrm{C}-4 \mathrm{H}$ interface and lateral expansion of $3 \mathrm{C}-\mathrm{SiC}$.

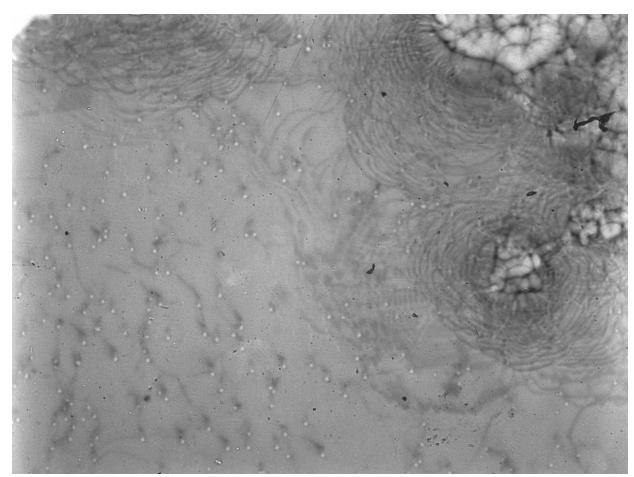

Fig. 5 SWBXT image taken in back reflection mode. White spots correspond to 3C-SiC. Networks of black lines around 3C are basal plan dislocations.

From a comparison of the full wafer mappings in Fig. 1 it can be seen that the measured reduction in carrier lifetime extends further than the actual presence of $3 \mathrm{C}$ inclusions. In order to reveal the nature of defects synchrotron white beam x-ray topography (SWBXT) was performed at the interface of $3 \mathrm{C}$ and $4 \mathrm{H}-\mathrm{SiC}$ on some selected areas on epilayer. Fig. 5 shows SWBXT image taken in back reflection mode. Big white spots on the right top corner are $3 \mathrm{C}$ inclusions which are surrounded by a network dislocation lines in the $4 \mathrm{H}$ region. These appear with high density at the interface between the $3 \mathrm{C}$ and $4 \mathrm{H}-\mathrm{SiC}$ and were generated during growth in order to compensate the lattice mismatch between the two polytypes. The high dislocation density in the $4 \mathrm{H}$ region around $3 \mathrm{C}$ inclusions reduces the measured carrier lifetime.

\section{Conclusions}

The growth of $4 \mathrm{H} \mathrm{SiC}$ epitaxial layers on nominally on-axis substrates has been studied. The polytype stability has been maintained over the larger part of the wafer, but $3 \mathrm{C}$ inclusions have not been possible to avoid. The $3 \mathrm{C}$ inclusions start only at the beginning of the growth and expand laterally without following any particular direction, probably originating from surface damages and not trough $3 \mathrm{D}$ nucleation. $\mathrm{KOH}$ etched wafer revealed that there is a less probability for $3 \mathrm{C}$ nucleation in the area with high dislocation density, also micropipe did not give rise to the nucleation of $3 \mathrm{C}$. Closely spaced $4 \mathrm{H}$ growth spirals did not produce any growth disturbance or $3 \mathrm{C}$ inclusions. High density of basal plan misfit dislocation at the interface between $3 \mathrm{C}$ and $4 \mathrm{H}$ regions caused lower crystal quality as observed through a reduced carrier lifetime around $3 \mathrm{C}$ regions.

\section{Acknowledgements}

This work was supported by the Swedish Research Council and Norstel AB via the project "Industrialization of SiC Material" funded by Vinnova and the Swedish Energy Agency.

\section{References}

[1] K.Shenai, R. S. Scott and B. J. Baliga: IEEE Transactions on Elctron Devices, vol. 36, no. 9, September 1998, p. 1811.

[2] M.Treu, R. Rupp, H. Brunner, F. Dahlquist and Ch. Hecht: Materials Science Forum Vols. 457460 (2004) p. 981.

[3] Jacobson, H.; Bergman, J.P.; Hallin, C.; Janzen, E.; Tuomi, T.; Lendenmann, H.: Journal of Applied Physics, v 95, n 3, 1 Feb. 2004, p 1485.

[4] C. Hallin, I. Ivanov, J. P. Bergman, E. Janzén: Materials Science Forum, 457- 460, (2003) p.193.

[5] O. Kordina, A. Henry, J. P. Bergman, N. T. Son, W. M. Chen, C. Hallin, and E. Janzén: Applied Physics Letters, v 66, n 11, 13 March 1995, p.1373.

[6] T. Kimoto and H. Matsunami: J. Appl. Phys. 78 (1995) p. 3132. 